\title{
Planejamento regional e a questão ambiental em Santa Catarina: caminhos e descaminhos ${ }^{1}$
}

\section{Regional planning and the environmental question in Santa Catarina: ups and downs}

\author{
Luciana BUTZKE ${ }^{2}$ \\ Ivo Marcos THEIS ${ }^{3}$
}

\begin{abstract}
RESUMO
O presente trabalho tem por objetivo analisar o planejamento regional e urbano em Santa Catarina tendo como referencial teórico e normativo o planejamento para o desenvolvimento territorial sustentável. Parte-se do pressuposto de que a experiência catarinense de planejamento possui características do planejamento convencional que prioriza a dimensão econômica, o curto prazo, é centralizado e trata inadequadamente as desigualdades regionais e urbanas, bem como a problemática ambiental. Examinase a experiência de planejamento em Santa Catarina, indicando as características do planejamento convencional e identificando os aspectos que apontam em direção ao planejamento para o desenvolvimento territorial sustentável - que recusa a ênfase na dimensão econômica, orienta-se para o longo prazo, é de natureza transdisciplinar, descentralizado e participativo. A questão proposta é analisada de forma a revelar os caminhos e descaminhos do planejamento regional e urbano em Santa Catarina, tendo como horizonte o planejamento para o desenvolvimento territorial sustentável.
\end{abstract}

Palavras-chave: planejamento regional; questão ambiental; Santa Catarina.

\begin{abstract}
This article aims to examine the regional and urban planning process in Santa Catarina taking as the theoretical and normative reference the "planning for sustainable territorial development" approach. It has been assumed that the Santa Catarina's experience of planning has characteristics of conventional

1 Uma versão anterior deste artigo foi apresentada no XII Encontro da ANPUR - que teve lugar em Belém/Pará, entre 21 e 25 de maio de 2007.

2 Cientista social, mestre em Sociologia Política pela Universidade Federal de Santa Catarina, pesquisadora do Núcleo de Pesquisas em Desenvolvimento Regional

3 Economista, doutor em Geografia pela Universidade de Tübingen (Alemanha), coordenador do Núcleo de Pesquisas em Desenvolvimento Regional, professor e
\end{abstract} e professora da UNIFEBE pesquisador da Universidade Regional de Blumenau. 
planning: it puts the economic dimension and the short term in the foreground, it is centralized, and it addresses the regional and urban inequalities, as well as the environmental issues, in an inadequate way. This contribution looks at the Santa Catarina's experience of planning by indicating the characteristics of the conventional planning process and by identifying those aspects that pointed towards a "planning for sustainable territorial development" process - a process which refuses to focus on the economic dimension, which is oriented to the long term, which considers transdisciplinarity, decentralization and social participation. The question is discussed in order to reveal the ups and downs of the regional and urban planning process in Santa Catarina, taking as horizon the "planning for sustainable territorial development” approach.

Key words: regional planning; the environmental question; Santa Catarina.

\section{Introdução}

"Você poderia me dizer, por favor, por qual caminho devo seguir agora?", perguntou ela. "Isso depende muito de aonde você quer ir”, respondeu o gato.

(Lewis Carroll, Alice no país das maravilhas apud SACHS, 2004, p. 9)

No Brasil, o planejamento do desenvolvimento em nível estadual caminha lado a lado com a experiência federal de planejamento. Os estados tornaram-se permeáveis à lógica do planejamento econômico para resolver problemas de desenvolvimento e estabelecer melhores relações com o governo federal. Em Santa Catarina, "a linha evolutiva da participação estatal na atividade econômica catarinense foi sempre condicionada pela cultura, estágio de desenvolvimento e ideologia dominantes em cada época e pela coerência com o modelo nacional” (SCHMITZ, 1985, p. 29).

O planejamento do desenvolvimento estadual se identifica, em grande medida, com o planejamento do desenvolvimento federal, sobretudo, no que se refere à ênfase na dimensão econômica, no curto e médio prazo, no tratamento setorial, nas dificuldades em lidar com as desigualdades regionais e urbanas e incorporar a problemática ambiental. Percebe-se, no caso catarinense, que o crescimento econômico impulsionado pela ação estatal, não levou a uma melhor distribuição da renda, à diminuição das desigualdades regionais e urbanas e a um melhor aproveitamento dos recursos naturais. "Não é necessário ter muita sensibilidade para perceber que grande parte da crise social e ecológica (catarinense) esteja intimamente associada a esta civilização dos negócios” (LENZI, 2000, p. 86).
Todavia, as discussões sobre as desigualdades regionais e urbanas, a problemática ambiental, a descentralização e a participação vão sendo incorporadas progressivamente na agenda do planejamento brasileiro e catarinense. Essas mudanças convergem, em alguma medida, para o enfoque do planejamento para o desenvolvimento territorial sustentável, que recusa o reducionismo econômico, direciona-se ao longo prazo, possui natureza transdisciplinar, contrapõe a lógica das necessidades à lógica do mercado e, em lugar de insistir nos instrumentos formais, aposta nos dispositivos institucionais que permitam a confrontação de valores e interesses dos diversos grupos sociais (GODARD; SACHS, 1975). O que aqui se pretende é descrever a prática do planejamento regional e urbano em Santa Catarina, analisar os aspectos dessa prática relacionados aos enfoques convencionais do planejamento e identificar características que apontam em direção ao planejamento para o desenvolvimento territorial sustentável.

Inicialmente, apresenta-se o referencial teórico. Em seguida, examinam-se as iniciativas governamentais de planejamento regional e urbano. Posteriormente, discute-se como a dimensão ambiental, a descentralização e a participação são incorporadas no planejamento. Na última seção destacam-se e se analisam as características do processo de planejamento regional e urbano em Santa Catarina que apontam na direção ao planejamento para o desenvolvimento territorial sustentável.

\section{Os limites do planejamento convencional e o enfoque do planejamento para o desenvolvimen- to territorial sustentável}

A experiência do planejamento estatal tem início após a Revolução Russa de 1917. O governo soviético que se 
instalou tinha como principal meta a reorganização da sociedade em bases administrativas para substituir o sistema capitalista de mercado. Nos países capitalistas centrais, o planejamento passou a ser valorizado após a crise de 1929. Na década de trinta, o governo dos Estados Unidos interveio no processo produtivo. No entanto, foi depois da Segunda Guerra Mundial que o planejamento econômico tomou mais forte impulso nos países capitalistas centrais.

Foi no final da década de 1940 que o planejamento encontrou terreno fértil nos países capitalistas periféricos. Na América Latina e na Ásia a construção de uma sociedade desenvolvida passou a ser uma das metas principais. Para isto foram elaborados planos com a ajuda de organizações internacionais - diga-se: presididas pelos países capitalistas centrais. O planejamento convergia com os imperativos da sociedade moderna, visando criar condições para o desenvolvimento capitalista. Para os países capitalistas periféricos o desenvolvimento aparecia como "salvação", cujo ápice seria chegar ao mesmo estilo de desenvolvimento dos países capitalistas centrais. A idéia difundida era a de que o planejamento levaria ao desenvolvimento (ESCOBAR, 2000).

No plano teórico, as investigações na área do planejamento contemplam diversas concepções. Para fins de apresentação e breve discussão, elegeram-se aqui, por serem estes mais conhecidos e debatidos, o planejamento racional compreensivo e o planejamento incremental, ambos identificados com o enfoque convencional de planejamento.

O planejamento racional compreensivo é conhecido também como totalizador racional, ortodoxo, sinótico (BRAYBROOKE; LINDBLOM, 1972). É o planejamento convencional realizado de maneira determinística e com base em previsões tidas como certas (MELO, 2001). Parecem evidentes os limites dessa concepção de planejamento. Os críticos desse enfoque enfatizam a impossibilidade de dispor a priori de um conjunto de informações suficientes para a formulação de objetivos e a dificuldade da escolha de alternativas num ambiente em rápida transformação (MELO, 1982). Os adeptos do enfoque racional compreensivo esquecem que o mundo é complexo, diverso, formado por muitos grupos e culturas, que assumem diferentes códigos de valores e costumam optar por diferentes dinâmicas de ação (OZBEKHAN, 1971).

$\mathrm{O}$ enfoque do incrementalismo disjunto é também conhecido como PMA (Partisan Mutual Adjustment - Ajuste mútuo entre partes) ou incrementalismo marginal, que tem como principal precursor C. Lindblom. Este enfoque prevê apenas pequenas mudanças no sistema. As grandes mudanças não seriam o objetivo do planejamento incremental (BRAYBROOKE; LINDBLOM, 1972; BUSTELO, 1982). O planejamento incremental de Lindblom, caracterizado pela lenta evolução das políticas que se alteram apenas marginalmente, pode também ser considerado um enfoque convencional de planejamento.

A proposta do planejamento para o desenvolvimento territorial sustentável surge como tentativa de romper com os limites do planejamento convencional. Ela tem início na discussão sobre o ecodesenvolvimento, incorporando, na seqüência, a teoria dos sistemas e o planejamento sistêmico. Ela agrega ainda contribuições da pesquisa-ação, da análise de conflitos, da pesquisa sobre recursos comuns, dos estudos sobre território e região e da análise prospectiva.

A construção da proposta tem início com a emergência da problemática sócio-ambiental, nas décadas de 1960/ 1970. Em 1973 Maurice Strong utilizou pela primeira vez o termo ecodesenvolvimento, que representava uma crítica ao modelo de desenvolvimento hegemônico. O conceito foi retomado em 1974 por Ignacy Sachs, tendo como princípios normativos a superação do reducionismo econômico e o alcance das finalidades sociais, a prudência ecológica, o envolvimento dos indivíduos e grupos no estabelecimento dos objetivos e dos meios do desenvolvimento, e o re-enquadramento da economia e de seus indicadores usuais (SACHS, 1986).

O conceito de desenvolvimento sustentável surgiu em 1987 e está associado à publicação do documento Nosso Futuro Comum, mais conhecido como Relatório Brundtland. O desenvolvimento sustentável enfatiza a satisfação das necessidades da geração atual sem desconsiderar as gerações futuras (CMMAD, 1988). Já a incorporação do território no enfoque do desenvolvimento sustentável é recente. O debate sobre as escalas espaciais é fundamental para o entendimento da realidade e a construção do desenvolvimento. Desde os anos 1990, o enfoque do ecodesenvolvimento tem sido enriquecido pela difusão de literatura sobre as dinâmicas de desenvolvimento sustentável e territorial. Nesse sentido, o conceito de territórios sustentáveis colabora para tornar o conceito de ecodesenvolvimento mais operacional, o que justifica a opção pelo conceito de desenvolvimento territorial sustentável (CAZELLA; VIEIRA, 2005).

O planejamento para o desenvolvimento territorial sustentável é entendido como um processo de decisão contí- 
nua antecipatória que entra no sistema racional de ação humana e interliga todos os elementos para direcioná-los aos resultados desejados. Ele está sempre presente na ação humana como um componente organizador. Regula a ação humana, não o meio ambiente ou a situação. È ditado pelos fins, não pelos meios. O objetivo do planejamento não é o de controlar os indivíduos, mas diminuir os distúrbios que muitas vezes as ações individuais criam no sistema como um todo. Quando a ação humana é compatível com valores compartilhados, os distúrbios sócio-ambientais são diminuídos e a coordenação das ações individuais pode ser alcançada sem a arbitrária restrição à liberdade individual, sem traduzir-se por um sistema rígido (OZBEKHAN, 1971).

O planejamento para o desenvolvimento territorial sustentável envolve a efetiva implementação de processos participativos que, por sua vez, demandam a descentralização político-administrativa, de tal forma que os atores locais possam ter condições efetivas de intervenção no processo de formulação e execução do planejamento. A integração da participação dos atores locais com o Estado, além de atores externos, permite a construção de processos de co-gestão, em que os interesses e relações interinstitucionais são negociados, de maneira a se estabelecerem as melhores formas de regulação do desenvolvimento (FEENY et al., 2001; BERKES, 2005).

A base desse planejamento é a explicitação dos valores e preferências dos grupos sociais e não pretende ser o atributo de técnicos, mas o instrumento de que um povo se vale para pensar e realizar seu futuro (GODARD; SACHS, 1975). Ao mesmo tempo, o planejamento não revela uma concepção inocente de unanimidade da sociedade. Ele faz da análise dos conflitos de valores e/ou interesses um dos elementos centrais para localizar as zonas de consenso possíveis e as zonas de conflitos irredutíveis.

Esse processo de diálogo compatibiliza um nível importante de participação, essencial para o ecodesenvolvimento. Para que ocorra essa participação, o planejador deve encorajar iniciativas locais, mas buscando compatibilizá-las com outras iniciativas e com o interesse geral no longo prazo. A tarefa do planejador é de harmonizar interesses socioeconômicos, ecológicos e culturais, definindo uma estratégia de desenvolvimento em equilíbrio com os princípios éticos da solidariedade sincrônica com os contemporâneos e diacrônica com as gerações futuras (SACHS, 1986).

As características aqui relacionadas ao enfoque do planejamento para o desenvolvimento territorial sustentá- vel e ao enfoque do planejamento convencional nortearão a descrição e análise do caso catarinense.

\section{O planejamento regional e urbano em Santa Catarina: iniciativas governamentais}

A primeira experiência de planejamento regional em Santa Catarina foi a dos Termos de Referência para os Planos Micro-Regionais de Desenvolvimento Integrado, que teve lugar na década de 1960, a partir de iniciativa do Serviço Federal de Habitação e Urbanismo (SERFHAU) e, depois, da Superintendência de Desenvolvimento do Sul (SUDESUL). O processo de planejamento partiu do nível microrregional, através das Associações de Municípios, que se formaram, espontaneamente, com o objetivo inicial de fortalecerem seus interesses políticos (SERFHAU, 1972). A SUDESUL estimulou esse processo através de ajuda financeira e orientação técnica para que os municípios se agrupassem. Ressalta-se como positiva a iniciativa espontânea das Associações de Municípios, mas como negativa a exclusão do Estado desse processo. Segundo Souto-Maior (1992), até esse ponto, os planos produzidos consistiram em um levantamento de dados e diagnósticos superficiais - que não saíram da prateleira.

Outra experiência importante de planejamento regional em Santa Catarina foi a da Política de Desenvolvimento Regional e Urbano de Santa Catarina (PDRU), formulada em 1981 pelo Gabinete de Planejamento (GAPLAN), no Governo de Jorge Bornhausen (1979-1983), do Partido Democrático Social (PDS). Ela contou com a colaboração técnica e financeira do Conselho Nacional de Desenvolvimento Urbano (CNDU), do Instituto de Desenvolvimento Econômico e Social (IPEA) e da Fundação Instituto Técnico de Economia e Planejamento (ITEP) (SANTA CATARINA, 1981).

\footnotetext{
Constituindo-se numa primeira tentativa de proposição de uma distribuição espacial desejável para as intervenções governamentais e para as transformações da realidade urbana e regional, a PDRU/SC deve buscar estabelecer um consenso acerca do conteúdo das ações públicas e privadas, no sentido de reduzir os desequilíbrios inter-regionais observados na organização espacial catarinense, ao mesmo tempo em que busca orientar a ação do aparelho administrativo do Estado na consecução do modelo territorial preconizado (SANTA CATARINA, 1981, p. 15-16).
} 
O objetivo geral da PDRU era a redução dos desequilíbrios regionais. Ela chamou atenção para alguns problemas da organização espacial catarinense: “a ausência de um sistema de planejamento regional integrado, a reduzida integração inter-regional, o crescimento das disparidades regionais em renda per capita, a insuficiência de ligações viárias no leste-oeste, o enfraquecimento das finanças públicas e a utilização predatória do meio ambiente” (SIEBERT, 2001, p. 146). A partir dos problemas levantados foram definidos objetivos específicos, cinco áreas homogêneas de intervenção e 96 diretrizes para as áreas de intervenção.

Em seguida, em 1986, foi elaborado o Atlas de Santa Catarina, no Governo Esperidião Amim (1983-1987), do PDS, com o objetivo de enriquecer o conhecimento sobre a realidade catarinense. Este documento foi elaborado pelo GAPLAN. Os dados foram extraídos do Censo de 1980 [IBGE] e apresentados na forma de mapas físicos e temáticos, gráficos, tabelas e textos de análise e comentários (SANTA CATARINA, 1986). Segundo Sérgio Sachet, na época Secretário Chefe do GAPLAN:

Colocando a geografia como uma fase de planejamento, principalmente em relação ao diagnóstico do todo espacial, o Atlas de Santa Catarina, através de seus mapas e textos, constitui um importante meio para a tomada de decisões. Seus capítulos, abrangendo os aspectos administrativos, físicos, humanos, econômicos, de serviços e estruturais urbanos, indicam as potencialidades e deficiências do Estado, demonstrando cartograficamente a base das relações exercidas no seu espaço (SANTA CATARINA, 1986, p. 7).

Na seqüência surgiu o documento Santa Catarina, Estado onde investir, organizado em 1990, no Governo Pedro Ivo Campos/Casildo Maldaner (1987-1990), do Partido do Movimento Democrático Brasileiro (PMDB), pela Secretaria de Estado da Indústria, do Comércio e do Turismo. O objetivo deste trabalho foi o de atrair investimentos internos e externos. Ele trouxe informações sobre o Estado (ocupação territorial, população, infra-estrutura, dados socioeconômicos e tecnologia) e foi o primeiro documento que caracterizou a especialização funcional produtiva do Estado. Este, contudo, se limitou a apresentar dados, não se configurando propriamente num plano com propostas e diretrizes (SIEBERT, 2001).
O Programa Integrado de Desenvolvimento SócioEconômico (PIDSE) foi elaborado em 1990, no Governo Casildo Maldaner, pelo Centro de Assistência Gerencial de Santa Catarina (CEAG/SC) e Centro de Apoio à Pequena e Média Empresa de Santa Catarina (atual Serviço Brasileiro de Apoio às Micro e Pequenas Empresas - SEBRAE).

\begin{abstract}
O PIDSE era um conjunto de diagnósticos municipais, com o objetivo de contribuir com o processo de municipalização no planejamento e gestão das ações municipais de caráter econômico, subsidiar as ações do Governo estadual e oportunizar informações aos interessados na expansão e/ou implantação de investimentos (SIEBERT, 2001, p. 149).
\end{abstract}

Nesse contexto, o Estado assumiu o papel de promotor e mobilizador do desenvolvimento econômico e social. O PIDSE (assim como o Santa Catarina, Estado onde investir) também se limitou a apresentar dados. Porém, apesar das limitações, ambos fizeram uma descrição do setor produtivo catarinense (SIEBERT, 2001).

Outra experiência a ser destacada é a do Plano Básico de Desenvolvimento Regional (PBDR). No final da década de 1980, a Associação de Municípios do Médio Vale do Itajaí (AMMVI) elaborou o Plano de Ordenamento Territorial quando o Prefeito de Blumenau, Vilson Kleinubing, era presidente da Associação. Posteriormente, quando foi eleito governador do Estado, no período de 1991 a 1994, pelo Partido da Frente Liberal (PFL), levou a idéia e estendeu a outras Associações de Municípios com o nome de Plano Básico de Desenvolvimento Regional (PBDR) (BIRKNER, 2004). Iniciado na gestão de Vilson Kleinubing e Konder Reis, transformou-se em Plano Básico de Desenvolvimento Ecológico-Econômico (PBDEE) na gestão seguinte, de Paulo Afonso (1995-1998), prosseguindo com este nome no governo de Esperidião Amim (1999-2002). Ele cobre o intervalo de 1992 a 1999, sendo o mais longo período contínuo de planejamento na história de Santa Catarina (SIEBERT, 2001).

Esse trabalho descentralizado só foi possível graças à eficiente estrutura do associativismo municipal catarinense, fenômeno característico de nosso Estado. As 18 Associações de Municípios que congregam os 261 municípios catarinenses, se articulam através da Federação Catarinense das Associações Municipais 
(FECAM) com o Governo do Estado e da União. Através delas, os municípios dispõem de assessoria técnica nas mais diversas áreas: legislativa, administrativa, urbanística, etc. Esta estrutura se forma espontaneamente, sem interferência do Estado, e ao longo dos anos evoluiu de maneira a refletir, em sua regionalização, os vínculos socioeconômicos e culturais que existem entre os municípios catarinenses (SANTA CATARINA, 1998, p. 7).

O objetivo dos Planos Básicos era a promoção do desenvolvimento integrado, sustentável e equilibrado. Através do convênio Governo - Associações de Municípios, os recursos eram repassados para que uma equipe técnica realizasse o plano, que era estruturado em duas partes: a situação presente e a proposta. O fator negativo da descentralização foi um desnível técnico entre os planos apresentados e a ausência de um plano para todo o Estado (SIEBERT, 2001).

O Zoneamento Ecológico Econômico (ZEE) foi elaborado em 1999, no segundo Governo de Esperidião Amim. Este teve por objetivo apontar as propostas básicas de desenvolvimento sustentável para uma determinada região.

O Zoneamento Ecológico Econômico surge [...] como um instrumento de gestão na busca da sustentabilidade. Cumpre destacar, contudo, que o zoneamento como instrumento de gestão prevê não só levantar o conhecimento técnico-científico disponível [...] mas também [...] estabelecer a participação sistemática dos agentes sociais que atuam na região (INSTITUTO CEPA, 2003, p. 3).

A elaboração do ZEE se deu de forma centralizada. Inovou apresentando cenários futuros e utilização de computação gráfica e geoprocessamento. Foram elaborados apenas dois ZEE: um para o Vale do Itajaí e outro para a Baixada Norte catarinense (INSTITUTO CEPA, 2003). Paralelo ao ZEE foi elaborado, pela Secretaria de Desenvolvimento e Meio Ambiente (SDM), o Plano de Gerenciamento Costeiro para o litoral de Santa Catarina, em consonância com o Plano Nacional de Gerenciamento Costeiro (PNGC), instituído pela Lei $\mathrm{n}^{\circ}$ 7661/88.

Outra tentativa de planejamento regional é a das $R e$ giões Metropolitanas. Essas foram instituídas em 1973, através da Lei Complementar $n^{\circ} 14$, de 8 de junho. O objetivo principal da região metropolitana era é "congregar os municípios que tenham uma relação entre si, para, juntos, elaborarem projetos e buscarem recursos, visando implementar obras de interesse regional - já que as de interesse local são atendidas pela respectiva municipalidade" (THEIS et al., 2001, p. 234). Em Santa Catarina foram criadas seis regiões metropolitanas, englobando todo o Estado: a Região Metropolitana Carbonífera, a de Florianópolis, a da Foz do Rio Itajaí, a do Norte/Nordeste Catarinense, a do Vale do Itajaí e a de Tubarão.

A criação de seis regiões metropolitanas tinha como propósito garantir o desenvolvimento regional equilibrado, já que a institucionalização de apenas uma região poderia concentrar investimentos e fluxos migratórios (MOURA; KLEINKE, 2000). Todavia, a criação das seis regiões foi baseada apenas em critérios políticos, não em definições geográficas e urbanísticas. A única região que vem passando por um processo de metropolização é a Região Metropolitana de Florianópolis. As demais nunca foram efetivamente implementadas (CARGNIN et al., 2006).

Outra tentativa de planejamento regional que se destaca foi a do Eixo Horizontal de Desenvolvimento e Integração, ligado ao Plano Plurianual (PPA). Em Santa Catarina, ele foi elaborado em 1999 pelo professor Alcides Abreu, com o apoio da Federação das Indústrias do Estado de Santa Catarina (FIESC), buscando integrar as diversas regiões do Estado (SIEBERT, 2001).

Em 2007 foi realizado um Estudo para subsidiar a abordagem da dimensão territorial do desenvolvimento nacional no Plano Plurianual 2008-2011 e no planejamento governamental de longo prazo. A Nota Técnica de Santa Catarina tratou de questões relativas à dinâmica demográfica, à especialização produtiva, à rede urbana e à infra-estrutura. Nesta Nota Técnica foram trabalhadas as tendências relacionadas a essas questões, cenários futuros e um breve exame da proposta de [re]regionalização proposta para o Estado de Santa Catarina (THEIS et al., 2007).

O Governo Luis Henrique da Silveira e Eduardo Pinho Moreira (2003-2006), por meio da Secretaria de Estado do Planejamento, Orçamento e Gestão (SPG), implementou uma estratégia de planejamento baseada na transformação de $29^{4}$ regiões administrativas em Secreta- 
rias de Desenvolvimento Regional (SDR). O plano contou com a parceria do Projeto Meu Lugar, do Programa das Nações Unidas para o Desenvolvimento (PNUD) (SANTA CATARINA, 2006).

A Secretaria de Estado do Planejamento, juntamente com outras secretarias e conselhos de desenvolvimento regional, com base em estudos e resultados da ação do governo e dos planos regionais elaborados pelas SDR, em parceria com o Projeto Meu Lugar (com o PNUD), elaborou o Plano Catarinense de Desenvolvimento SC 2015 (PCD). O plano compõe-se de diretrizes e estratégias para a ação governamental, tendo como horizonte o desenvolvimento equilibrado e sustentável de longo prazo. O PCD repousa numa análise retrospectiva do desenvolvimento de Santa Catarina, assim como num cenário tendencial e num cenário normativo (SANTA CATARINA, 2007).

O processo de reestruturação implementado pelo Governo de Luis Henrique da Silveira e Eduardo Pinho Moreira (2003-2006) inovou, principalmente, através da parceria com o Projeto Meu Lugar. Este tem como princípios a valorização do desenvolvimento endógeno e do capital social dos territórios e o envolvimento da comunidade regional no planejamento (TURNES et al., 2004). As SDR, por sua vez, deveriam facilitar a solicitação de verbas - que agora pode ser feita na própria região (SIEBERT, 2006).

Com a reeleição de Luis Henrique da Silveira - agora, tendo como vice Leonel Pavan - para o quadriênio 20072010, foram criadas mais seis SDR além das 30 já criadas na gestão anterior (JORNAL DE SANTA CATARINA, 2007). Apesar do posicionamento inovador, as 36 SDR têm sido duramente criticadas por serem compostas, no total, por 418 cargos, e por serem os cargos distribuídos em função dos interesses acomodados no interior da chamada tríplice aliança [PMDB, PSDB e DEM] $]^{5}$. O critério adotado seria a percentagem de votos recebidos pelos respectivos partidos na última eleição.

De fato, as 36 SDR contam com um recorte territorial que difere do recorte das associações de municípios, dos FDR, dos Comitês de Bacia Hidrográfica e das regiões metropolitanas. Mais: ao criar as SDR, o governo adotou uma estratégia de descentralização concebida "de cima para baixo”, ao invés de valorizar e estimular as iniciativas endógenas de planejamento regional já existentes no Estado.

Quanto, em geral, às iniciativas de planejamento regional em Santa Catarina até aqui apresentadas, nota-se uma preocupação crescente com as desigualdades regionais e urbanas. Contudo, um traço é a descontinuidade: muda governo, muda o plano e mudam as prioridades. Períodos de continuidade são exceção.

\section{A dimensão ambiental e o planejamento}

O Estado de Santa Catarina deu início à implantação de uma estrutura voltada aos problemas ambientais em 1975, com a criação da Secretaria de Tecnologia e Meio Ambiente (SETMA), do Conselho Estadual de Tecnologia e Meio Ambiente (CETMA) e da Fundação de Amparo à Tecnologia e Meio Ambiente (FATMA). O CETMA e a FATMA foram vinculados a SETMA até 1977, quando a Secretaria foi extinta pela Lei $\mathrm{n}^{\circ} 5.292$ (MASSIGNAN, 1995). A SETMA ficou localizada funcionalmente na área econômica da estrutura do governo estadual. Seu primeiro e único secretário foi Augusto Batista Pereira, fundador e proprietário da Carbonífera Treviso S/A e da Treviso Agrícola S/A (BORINELLI, 1998).

\footnotetext{
Constatou-se a existência de uma estrutura voltada para o meio ambiente, contudo sem articulação entre os órgãos que a compõem, mesmo entre as gerências da SETMA, especialmente as subordinadas a Diretorias diferentes. Por outro lado, a junção de diversas áreas tecnologia, energia, indústria, comércio, turismo e meio ambiente - dentro de uma mesma Secretaria de Estado, demonstrou a dificuldade em interrelacionar interesses conflitantes. Observou-se que a Diretoria de Meio Ambiente da SETMA dispunha de um quadro de pessoal restrito, sem corpo técnico, sem equipamentos e sem recursos para executar suas atribuições (MASSIGNAN, 1995, p. 143).
}

5 Consta que a distribuição seria a seguinte: PMDB com 188 cargos, PSDB com 100, DEM com 88 e a cota de LHS e o restante da base aliada [PDT, PPS e PTB] com 42 cargos (JORNAL DE SANTA CATARINA, 2007). 
Além da criação da SETMA houve uma preocupação crescente, em nível governamental com a criação de unidades de conservação. Em 1975 foi criado o Parque Estadual da Serra do Tabuleiro (SANTA CATARINA, 1986). Nesse período, ainda teve início o controle de balneabilidade, realizou-se o levantamento da cobertura vegetal pela SUDESUL e IBDF, e fez-se a prospecção do calcário em Santa Catarina pela SUDESUL (BORINELLI, 1998).

Na primeira gestão da FATMA, o presidente foi Idaulo José Cunha, que liderava a corrente da "gestão ambiental”, em contraposição a corrente "conservacionista”, liderada por Raulino Reitz. A primeira priorizava os problemas ambientais, enquanto a segunda a criação de unidades de conservação, pesquisa, levantamentos e restauração da fauna e flora do Estado (BORINELLI, 1998).

No Governo Konder Reis (1975-1979), o trabalho da FATMA, que deveria ser de fiscalização, foi prejudicado. Por exemplo, nesse período houve pouca preocupação com o controle da poluição. Em 1977, com o Decreto ${ }^{\circ}$ 2.490, a supervisão da FATMA passou para a Secretaria de Assuntos da Casa Civil. Com essa mudança, a FATMA passou da área econômica para a área política do governo (BORINELLI, 1998). Em 1979, com a criação do Gabinete de Planejamento (GAPLAN), pela Lei n ${ }^{\circ}$ 5.516, a FATMA volta a mudar de abrigo: ela passa, então, a ser supervisionada pelo GAPLAN (MASSIGNAN, 1995).

No Governo Jorge Bornhausen (1980-1983) houve avanços no campo do meio ambiente: a aprovação e regulamentação da primeira lei estadual do meio ambiente, o início da regionalização da FATMA, através do COMDEMA (Conselho Municipal de Defesa Ambiental) e das secretarias regionais da FATMA, e a divulgação da temática ambiental nos meios de comunicação. No entanto, nesse mesmo governo, houve impressionante rotatividade de dirigentes da FATMA: cinco em quatro anos (BORINELLI, 1998).

Em 1991 ocorreu a neutralização do CETMA e, depois, dos COMSEMAs (Conselhos de Meio Ambiente), como conseqüência da centralização do poder decisório nas mãos do diretor do órgão ambiental e do secretário do órgão ao qual a FATMA estava subordinada.

O licenciamento de atividades poluidoras foi adotado como principal instrumento de política de controle da poluição e degradação ambiental, com a aprovação da Lei $\mathrm{n}^{\circ}$ 5.793, de 15 de outubro de 1980, e sua regulamentação através do Decreto $\mathrm{n}^{\circ} 14.250$, de 5 de junho de 1981 . O “controle de polícia” passou, pois, para a FATMA.

O período que vai de 1975 a 1982 pode ser "entendido como um período conservador/oligárquico na administração pública estadual, mesmo com as diferenças de abordagem da questão, tiveram sucesso na missão de não alterar as formas tradicionais de apropriação dos recursos naturais” (MASSIGNAN, 1988, p. 151). A função da FATMA em todo esse período foi a de administrar a crise ambiental, não de solucioná-la (MASSIGNAN, 1988).

No Governo Esperidião Amin (1983-1986) criou-se o Conselho de Defesa Ambiental (CODAM), a Secretaria Extraordinária da Reconstrução (SER), o Conselho Extraordinário de Reconstrução (CER), o Serviço Especial de Defesa Comunitária (DECOM), a Comissão Estadual de Controle de Agrotóxicos (CECA) e o Conselho Estadual de Recursos Hídricos (CERH). Novas entidades da sociedade civil surgem nesse período: o Movimento Ecológico Livre (MEL) e o Partido Verde (PV) em 1985 (BORINELLI, 1998). Ocorreu também uma maior participação comunitária na resolução de conflitos ambientais. Esse governo ampliou o potencial do espaço da ação da política ambiental. Porém, “os programas do Governo Amin pareciam compreendendo os problemas ambientais isoladamente e assim divorciados das políticas econômicas, de ciência e tecnologia e de recursos minerais” (BORINELLI, 1998, p. 156).

No Governo Pedro Ivo Campos/Casildo Maldaner (1987-1990) veio à luz, a partir do movimento ambientalista, a Federação de Entidades Ecologistas Catarinense (FEEC). Foi também nesse período que se consolidou um novo agente público, o Ministério Público Estadual e Federal, que passou a disputar com a FATMA e o IBAMA a produção de versões dos problemas ambientais. Na fase que vai de 1987 a 1989, várias medidas aumentaram a autonomia das sedes regionais da FATMA, agora chamadas de Gerências Regionais. Mesmo com os avanços, os "fatores políticos eleitorais e crises ambientais pontuais são as principais lógicas que governam a dinâmica das sedes regionais da FATMA" (BORINELLI, 1998, p. 208). Em 1987 foi criada a Secretaria de Desenvolvimento Urbano e Meio Ambiente (SEDUMA), mudando novamente a vinculação da FATMA (MASSIGNAN, 1995). Parece, porém, que "em nenhum dos governos anteriores a preocupação ambiental estivera tão articulada com as demais áreas de ação do governo, inclusive a econômica" (BORINELLI, 1998, p. 193).

No Governo Vilson Kleinubing (1991-1994), com a 
reforma administrativa realizada em 1991, através da Lei $\mathrm{n}^{\circ}$ 8.245, foi criada a Secretaria de Estado de Tecnologia, Energia e Meio Ambiente (STM). Esta Secretaria incorporou todas as funções da Secretaria de Estado da Indústria, Comércio e Turismo, da Secretaria de Estado da Ciência, Tecnologia, Minas e Energia e as funções atinentes ao Meio Ambiente da SEDUMA, exercendo-as diretamente ou através de órgãos vinculados, como as Centrais Elétricas de Santa Catarina S/A (CELESC), Santa Catarina Turismo S/ A (SANTUR), FATMA, Junta Comercial de Santa Catarina etc. (MASSIGNAN, 1995, p. 65).

De 1991 em diante, a FATMA passou a se chamar, através da Lei $n^{\circ}$ 8.245, apenas Fundação do Meio Ambiente. Atualmente, a FATMA tem como missão garantir a preservação dos recursos naturais do Estado. Atua na gestão de oito unidades de conservação estaduais; na fiscalização, buscando evitar a degradação, exploração e extinção de recursos naturais; no licenciamento ambiental; no programa de prevenção e atendimento a acidentes com cargas perigosas; no geoprocessamento; nos estudos, pesquisas ambientais e publicações técnicas e na pesquisa de balneabilidade (FATMA, 2006).

Em síntese, pode-se afirmar que a questão ambiental em Santa Catarina foi mantida na marginalidade política: "O aparato do meio ambiente, em quase todos os governos, ocupou uma posição subalterna e isolada na estrutura administrativa estadual, conforme demonstraram os planos de governo" (BORINELLI, 1998, p. 220). Ainda mais:

a política ambiental do Estado de Santa Catarina carece de consistência, continuidade e interação entre os diversos setores da administração pública e destes com a sociedade civil [...] O governo do Estado "reorganiza" sua estrutura a cada gestão, mas não instrumentaliza a administração burocrática para o exercício de suas atribuições, nem verifica as necessidades reais dos setores criados, extintos ou adaptados (MASSIGNAN, 1995, p. 149-50).

É inequívoco, pois, que a trajetória da incorporação das questões ambientais pelo poder público estadual catarinense foi errática. O tratamento dispensado à problemática ambiental foi setorializado e subalterno. Em termos político-administrativos, faltaram consistência e continuidade. Sobretudo, não houve articulação entre as experiências de planejamento e o setor ambiental do governo.

\section{A descentralização e a participação regional no planejamento}

As iniciativas de descentralização e participação estão previstas desde o "Seminário Sócio-Econômico de Santa Catarina" que, posteriormente, motivaria a experiência do PLAMEG I. Em maior ou menor grau, a descentralização e a participação passam a estar presentes nas ações governamentais desde a década de 1960.

Paralela à ação governamental, observam-se experiências a partir das próprias regiões. Uma iniciativa descentralizadora em Santa Catarina foi o processo de criação das fundações regionais de ensino superior, iniciado na década de 1960, em resposta à falta de uma política estatal. As Associações de Municípios surgem na mesma década e os Fóruns de Desenvolvimento Regional Integrado aparecem na década de 1990 (BIRKNER, 2004).

A primeira Associação de Municípios de Santa Catarina foi fundada em 1961. Atualmente, existem 21 Associações de Municípios. Elas surgiram com a finalidade básica de aumentar o poder reivindicatório dos municípios junto aos órgãos estatais para a resolução de problemas comuns (SOUTO-MAIOR, 1992). Dentre os objetivos que norteiam a atuação das Associações de Municípios estão o desenvolvimento em nível regional através da técnica de planejamento e a prestação de serviços e assistência técnica aos municípios associados (KRAUS, 1991).

As Associações de Municípios de Santa Catarina tem tido uma atuação importante em nível regional e estadual. No nível estadual, participaram ativamente dos Termos de Referência na década de 1960 e, em maior ou menor grau, de todas as iniciativas de planejamento regional que se sucederam. No nível regional, contam com iniciativas desde as próprias municipalidades.

A atuação recente das associações de municípios demonstra avanços e dificuldades. As comunidades participam de forma ainda muito tímida das tomadas de decisão no campo do planejamento, permanecendo o poder de decisão concentrado nos gabinetes dos prefeitos e nas assembléias das respectivas associações, nas quais somente os prefeitos participam. A ênfase na prestação de serviços faz com que o planejamento sistêmico e o longo prazo fiquem de lado. Dessa forma, as associações, apesar dos quarenta anos de funcionamento, dispõem de um espaço muito restrito de reflexão e potencial limitado para formular estratégias alternativas de desenvolvimento (BUTZKE, 2007).

Outra iniciativa regional importante é a dos Comitês 
de Gerenciamento de Bacias Hidrográficas. Eles surgiram na década de 1990, através da Política Nacional de Recursos Hídricos (Lei 9493/97). Eles têm como unidade a bacia hidrográfica e como objetivo organizar o processo de descentralização da gestão dos recursos naturais, elegendo prioridades locais e estabelecendo estratégias e diretrizes políticas. Os comitês são compostos por integrantes assim distribuídos: 40\% de usuários da água, 20\% de governos estadual e federal e $40 \%$ da população e sociedade civil. Atualmente existem 15 Comitês constituídos (THEIS et al., 2007). A preocupação dos comitês de gerenciamento das bacias hidrográficas com a questão da água é central e sua estrutura possibilita a participação de muitos atores sociais. Todavia, a sua atuação é restrita se observados os critérios do desenvolvimento territorial sustentável.

Uma terceira forma de organização regional é a dos Fóruns de Desenvolvimento Regional (FDR). Tem-se em Santa Catarina um processo de descentralização que iniciou na década de 1960, com a criação das Associações de Municípios, e continuou na década de 1990, com a criação dos Fóruns e depois das Agências de Desenvolvimento Regional. O primeiro Fórum de Desenvolvimento Regional Integrado foi criado em 1996, em Chapecó, por iniciativa da Associação de Municípios do Oeste de Santa Catarina (AMOSC). Na seqüência foi criado o Fórum Catarinense de Desenvolvimento (FORUMCAT), com o fim de congregar todos os fóruns regionais (BIRKNER, 2004).

O FORUMCAT incorporou os preceitos da Agenda 21 catarinense organizada a partir de 2000. No I Seminário Internacional sobre Desenvolvimento Local e Sustentável, organizado pelo FORUMCAT, em agosto de 2001, originou-se a Carta de Chapecó que define que as estratégias de desenvolvimento regional do Estado devem contemplar quatro dimensões: política, social, econômica e ambiental (BIRKNER, 2004).

O Governo Esperidião Amin (1999-2002) apoiou essa iniciativa. Porém, o governo que o sucedeu adotou uma nova estratégia: criou, como se viu, 36 SDR, com outro recorte territorial, que difere do recorte das Associações de Municípios e dos Fóruns. As Associações de Municípios tem quatro décadas de história e de parceria com o governo estadual, independente da vinculação partidária. Os FDRI contam com uma década de experiência. O governo de Luiz Henrique da Silveira adota uma estratégia de descentralização concebida "de cima para baixo" (topdown), ao invés de valorizar e estimular as iniciativas de planejamento regional desde as próprias regiões.

\section{Perspectivas do planejamento em Santa Catarina: o caminho depende de aonde se quer ir}

No meio do caminho tinha uma pedra tinha uma pedra no meio do caminho tinha uma pedra no meio do caminho tinha uma pedra. Nunca me esquecerei desse acontecimento na vida de minhas retinas tão fatigadas. Nunca me esquecerei que no meio do caminho tinha uma pedra tinha uma pedra no meio do caminho no meio do caminho tinha uma pedra.

Carlos Drummond de Andrade, No meio do Caminho

O presente artigo teve por objetivo analisar o planejamento regional e urbano em Santa Catarina, tomando por referencial teórico e normativo o planejamento para o desenvolvimento territorial sustentável. Em vista desse propósito, partiu-se do pressuposto de que o planejamento regional e urbano em Santa Catarina é, em larga medida, convencional. Entende-se que seja convencional por ter priorizado a dimensão econômica, privilegiado o curto prazo, assumido um caráter centralizado e setorializado, e tratado inadequadamente as desigualdades regionais e a problemática ambiental. Contudo, a partir das discussões sobre desigualdades regionais e urbanas (na década de 1950/ 1960), a problemática ambiental (na década de 1970), a descentralização e a participação (na década de 1980), constatam-se algumas mudanças.

Além da ênfase na dimensão econômica, o planejamento regional catarinense caracteriza-se também por iniciativas top-down (na contramão das iniciativas desde as próprias regiões), pela descontinuidade dos planos (que, via de regra, mudam a cada troca de governo), e pela continuada dificuldade de incorporação da dimensão ambiental - relacionada à gestão setorializada e com perfil reativoremedial, muito voltada à preservação, pouco articulada com outras ações de desenvolvimento. A descentralização e a participação avançam com a experiência das associações de municípios e os FDRI. Todavia, nem sempre contam com o apoio do governo estadual.

Percebem-se avanços consideráveis no campo normativo, institucional e operacional no planejamento regional e urbano no Brasil e em Santa Catarina: as leis 
mudaram, instituições foram criadas, novos instrumentos de planejamento e gestão foram instituídos. Esses avanços são importantes, mas não levam necessariamente ao desenvolvimento territorial sustentável. Subsistem muitas práticas relacionadas ao enfoque convencional de planejamento. É preciso que haja efetiva descentralização e democratização em todos os níveis para que não se perpetue a cultura política clientelista, conservadora e ainda fortemente marcada por resquícios autoritários. O planejamento do desenvolvimento deveria abrir-se de maneira mais efetiva "à participação autêntica das forças vivas da sociedade civil e à integração transsetorial e interinstitucional” (VIEIRA; RIBEIRO, 2006).

\section{Referências}

BERKES, Fikret. Conexões Institucionais transescalares. In: VIEIRA, P. H. F., BERKES, F.; SEIXAS, C. S. Gestão integrada e participativa de recursos naturais: conceitos, métodos e experiências. Florianópolis: Secco/APED, 2005, p. 293332.

BIRKNER, Walter Marcos Knaesel. Capital social e reformas políticas em Santa Catarina: o caso dos Fóruns de Desenvolvimento Regional Integrado. Campinas. 313 p. Tese (Doutorado) “ Departamento de Filosofia e Ciências Humanas, Universidade Estadual de Campinas, Campinas, 2004.

BORINELLI, Benilson. Um fracasso necessário: política ambiental em Santa Catarina e debilidade institucional (19751991). 234 p. Dissertação (Mestrado) “ Curso de Pós-Graduação em Administração, Centro Sócio-Econômico, Universidade Federal de Santa Catarina, Florianópolis, 1998.

BRAYBROOKE, David; LINDBLOM, Charles E. Uma estratégia de decisão social: escolha de políticas alternativas como processo social. Rio de Janeiro: Zahar, 1972.

BUSTELO, Eduardo S. Planejamento e política social: a dialética do possível. In: BROMLEY, Ray; BUSTELO, Eduardo S.(Org.). Política x Técnica no planejamento: perspectivas críticas. São Paulo e Brasília: Editora Brasiliense e UNICEF, 1982, p. 132-152.

BUTZKE, Luciana. O papel das associações de municípios na dinâmica de planejamento regional e urbano em Santa Catarina. Estudo de caso sobre a trajetória da Associação dos Municípios do Alto Vale do Itajaí. 142p. Dissertação
Se o caminho desejável é o do desenvolvimento sócio-ambientalmente sustentável, um primeiro passo poderia ser a valorização das iniciativas de planejamento desde as próprias regiões. Em Santa Catarina, estas têm sido desencadeadas principalmente pelas associações de municípios e pelos FDRI. No entanto, embora seja necessário, este passo ainda seria insuficiente. Existem outros caminhos, no meio dos quais também se vão encontrar pedras. Mas, se a experiência de mais de meio século de planejamento conduziu a sociedade de Santa Catarina por tantos descaminhos, talvez tenha finalmente chegado o momento de um novo desafio: o planejamento para o desenvolvimento territorial sustentável.

(Mestrado) - Programa de Pós-graduação em Sociologia Política, Centro de Filosofia e Ciências Humanas, Universidade Federal de Santa Catarina, Florianópolis, 2007.

CARGNIN, Vanessa E. et al. Região Metropolitana de Florianópolis/SC: aglomeração urbana ou metropolização? In: REUNIÃO ANUAL DA SBPC, 58., jul. 2006, Florianópolis. Anais... Disponível em: < http://www.sbpcnet.org.br/livro/58ra/ SENIOR/RESUMOS/resumo_611. html>. Acesso em: 20/12/ 2007.

CAZELLA, Ademir; VIEIRA, Paulo H. Freire. Modelo de análise referente ao projeto de pesquisa Desenvolvimento territorial sustentável: diagnóstico de potencialidades e obstáculos em zonas rurais dos estados da Paraíba e Santa Catarina. Florianópolis: [s.n.], 2004.

ESCOBAR, Arturo. Planejamento. In: SACHS, Wolfgang. Dicionário do desenvolvimento: guia para o conhecimento como poder. Petrópolis: Vozes, 2000, p. 211-228.

FATMA. O que é a FATMA. Disponível em: <http:// www.fatma.sc.gov.br/>. Acesso em: 19/7/2006.

FEENY, D. et al. A tragédia dos comuns: vinte e dois anos depois. In: DIEGUES, A.C.; MOREIRA, A. C. (Orgs.). Espaços e recursos naturais de uso comum. São Paulo: NUPAUBUSP, 2001, p. 17-42.

GODARD, Olivier; SACHS, Ignacy. L'environnement et la planification. In: BARRAU, J. et al. Environnement et qualité de la vie. Paris, Guy lê prat (col. Bibliotheque de 
l'environnement, dirigée par Jean A. Ternisien), 1975, p. $207-$ 247.

INSTITUTO CEPA. Zoneamento Ecológico-Econômico: Vale do Itajaí. execução Instituto CEPA - SC. Florianópolis: Instituto CEPA, 2003.

GERÊNCIAS em Blumenau serão escolhidas até final do mês. Jornal de Santa Catarina, Blumenau, sábado e domingo, 14 e 15 abr. 2007, p. 4.

KRAUS, Pedro Guilherme. Associativismo intermunicipal e planejamento microrregional em Santa Catarina. Dissertação. Florianópolis. UFSC, 1991.

LENZI, Cristiano Luis. O "modelo catarinense" de desenvolvimento: uma idéia em mutação? Blumenau: Ed. da Furb, 2000.

MASSIGNAN, Soraya. Política ambiental do Estado de Santa Catarina: 1975 - 1994. 164 p. Dissertação (Mestrado) “ Pós-Graduação em Administração, Universidade Federal de Santa Catarina, Florianópolis, 1995.

MELO, Maria Ângela Campelo de. Planejamento em tempo de incerteza: um paradoxo? Revista de Ciência e Tecnologia RECITEC, Recife, v. 5, p. 171-186, 2001. Disponível em: $<$ www.fudaj.gov.br/rtec/art/art-027.html>. Acesso em: 15/8/ 2005.

MOURA, Rosa; KLEINKE, Maria de Lourdes Urban. Espacialidades e institucionalidades: uma leitura do arranjo sócio-espacial e do modelo de gestão das regiões metropolitanas do sul do Brasil. In: ENCONTRO ANUAL DAANPOCS, 24., out. 2000. Petrópolis. Anais...

OZBEKHAN, Hasan. Planning and Action. In: WEISS, P. A. (Ed.). Hierarchically Organized Systems in Theory and Practice. Hafner: New York, 1971, p. 123-230.

SACHS, Ignacy. Ecodesenvolvimento: crescer sem destruir. São Paulo: Vértice, 1986.

SANTA CATARINA. Secretaria de Planejamento e Gestão. Instituto Celso Ramos. Plano Catarinense de Desenvolvimento SC 2015. Disponível em: <http://www.spg.sc.gov.br/>. Acesso em: 30/1/2007.

SANTA CATARINA. Secretaria de Planejamento e Gestão. Plano Catarinense de Desenvolvimento (PCD): Descentralização e o Desenvolvimento Regional Sustentável. Disponível em: <http://www.spg.gov.br>. Acesso 15/7/2006.

SANTA CATARINA. Secretaria de Estado do Desenvolvimento Urbano e Meio Ambiente SDM. Plano Básico de Desenvolvimento Ecológico-Econômico: Associação de Municípios do Médio Vale do Itajaí. Florianópolis: SDM, 1998.

SANTA CATARINA. Gabinete de Planejamento e Coordenação Geral. Subchefia de Estatística, Geografia e Informática. Atlas de Santa Catarina. Rio de Janeiro: Aerofoto Cruzeiro, 1986.

SANTA CATARINA. Gabinete de Planejamento e Coordenação Geral. Subchefia para a Política de Desenvolvimento Regional. Política de Desenvolvimento Regional e Urbano para Santa Catarina. Florianópolis, 1981.

SCHMITZ, Sérgio. Planejamento estadual: a experiência catarinense com o Plano de Metas do Governo - PLAMEG 1961/1965. Florianópolis: Ed. Da UFSC, FESC/UDESC, 1985.

SERFHAU. Planejamento a nível microrregional: anais do III Curso Intensivo de Planejamento Urbano e Local. Brasília, DF, 1972.

SIEBERT, Claudia. Endogenia e heteronomia: a experiência de Santa Catarina com o Projeto Meu Lugar. In: SEMINÁRIO INTERNACIONAL SOBRE DESENVOLVIMENTO REGIONAL, Santa Cruz do Sul. Anais... Santa Cruz do Sul: UNISC, 2006.

SIEBERT, Claudia. Panorama do planejamento regional em Santa Catarina: da descentralização à construção da solidariedade regional. In: SIEBERT, Claudia (Org.). Desenvolvimento regional em Santa Catarina. Blumenau: Edifurb, 2001, p. 139-166.

SOUTO-MAIOR, Joel. A problemática da coordenação, cooperação e planejamento intermunicipais no Brasil. Revista de Administração Municipal, Rio de Janeiro: IBAM, v. 39, n. 204, p.49-65, jul./set.1992.

THEIS, Ivo Marcos et al. Globalização e planejamento do desenvolvimento regional: o caso do Vale do Itajaí. In: SIEBERT, Claudia (Org.). Desenvolvimento regional em Santa Catarina: reflexões, tendências e perspectivas. Blumenau: Edifurb, 2001, p. 213-244.

THEIS, Ivo Marcos et al. Nota técnica: Subsídio à abordagem da Dimensão Territorial do desenvolvimento nacional do Plano Plurianual e no Planejamento Governamental de Longo Prazo. Brasília: CGEE, 2007.

TURNES, Valério et al. Projeto meu lugar: transformar regiões administrativas em territórios de desenvolvimento. Florianópolis: Cidade Futura, 2004.

VIEIRA, Paulo H. Freire; RIBEIRO, Maurício Andrés. Políticas ambientais no Brasil: gênese, evolução e desafios socioinstitucionais, 2006 (no prelo). 